\title{
Environmental life cycle assessment of Indian coal-fired power plants
}

\author{
Udayan Singh $^{1} \cdot$ Naushita Sharma $^{1} \cdot$ Siba Sankar Mahapatra ${ }^{1}$
}

Received: 23 October 2015/Revised: 6 January 2016/Accepted: 22 February 2016/Published online: 1 July 2016

(C) The Author(s) 2016. This article is published with open access at Springerlink.com

\begin{abstract}
Coal is the backbone of the Indian power sector. The coal-fired power plants remain the largest emitters of carbon dioxide, sulfur dioxide and substantial amounts of nitrogen oxides, which are associated with climate and health impacts. Various $\mathrm{CO}_{2}$ mitigation technologies (carbon capture and storage-CCS) and $\mathrm{SO}_{2} / \mathrm{NO}_{x}$ mitigation technologies (flue gas desulfurization and selective catalytic reduction) have been employed to reduce the environmental impacts of the coal-fired power plants. Therefore, it is imperative to understand the feasibility of various mitigation technologies employed. This paper attempts to perform environmental life cycle assessment (LCA) of Indian coal-fired power plant with and without $\mathrm{CO}_{2}, \mathrm{SO}_{2}$ and $\mathrm{NO}_{x}$ mitigation controls. The study develops new normalization factors for India in various damage categories, using the Indian emissions and energy consumption data, coupled with the emissions and particulate emission to come up with a final environmental impact of coal-fired electricity. The results show a large degree of dependence on the perspective of assessment used. The impact of sensitivities of individual substances and the effect of plant efficiency on the final LCA results is also studied.
\end{abstract}

Keywords Life cycle assessment · Coal-fired power plants · Carbon capture and storage · Environmental impact · Plant inventory $\cdot$ Flue gas desulfurization

\section{Introduction}

Coal is the backbone of the Indian power sector. The coalbased power sector in India has expanded steadily and significantly from about $750 \mathrm{MW}$ at the time of independence to more than $160 \mathrm{GW}$ today (CEA 2013a, b). Further expansion in the coal-fired capacity is expected in the near future with coal expected to continue dominating India's primary energy demand as well as electricity generation (Garg and Shukla 2009; Chikkatur et al. 2009). However, such power plants are also amongst the largest sources of emissions of carbon dioxide $\left(\mathrm{CO}_{2}\right)$, sulphur dioxide $\left(\mathrm{SO}_{2}\right)$, nitrogen oxides $\left(\mathrm{NO}_{x}\right)$ and particulate matter $(\mathrm{PM})$. If no

Siba Sankar Mahapatra

ssm@nitrkl.ac.in

1 Department of Mechanical Engineering, National Institute of Technology Rourkela, Rourkela, India major policy changes or mitigation strategies are put into place, these emissions are expected to rise manifold in the future. Further, the contribution of the power sector is also increasing in the all-India emissions scenario. For instance, the contribution of power plants to the national $\mathrm{SO}_{2}$ emissions was $30.25 \%$ in 1985, which increased to $56.67 \%$ in 2005. Similarly, the contribution of the power sector to allIndia $\mathrm{CO}_{2}$ emissions increased from 33.18 to $51.91 \%$ during the said period (Garg et al. 2006). This is so because of the targets for large-scale electrification for various parts of the country. For instance, the setting up of Ultra Mega Power Plants (UMPPs), which are plants of around $4 \mathrm{GW}$ each, is expected to bridge the large electricity deficit in the country. Also, there are pollutant-specific reasons for rise in emissions. For example, the increase in the use of high-sulphur imported coal is a reason for growing $\mathrm{SO}_{2}$ emissions.

Various mitigation strategies have been suggested in the literature for control of such emissions from power plants. $\mathrm{CO}_{2}$ capture and storage (CCS) is one of the most prominent 
technologies talked about for control of anthropogenic $\mathrm{CO}_{2}$ emissions (IPCC 2005). Flue gas desulfurization (FGD) and selective catalytic reduction (SCR) technologies are typically employed in thermal power plants for $\mathrm{SO}_{2}$ and $\mathrm{NO}_{x}$ mitigation respectively. The amount of adoption of such mitigation technologies is quite different globally. For instance, CCS is still in the research/demonstration phase in various parts of the world. However, FGD and SCR are widely used globally (Rubin et al. 2004). Nevertheless, the adoption of FGD and SCR in India is currently limited mostly to plants using imported coal. Recently, the issue of FGDs has been raised in several avenues (Guttikunda and Jawahar 2014). The implications of CCS, FGD and SCR on Indian coal-fired power plants have also been discussed in literatures lately (Karmakar and Kolar 2013; Singh and Rao 2014a, b, 2015). This paper attempts to perform an environmental life-cycle assessment (LCA) of coal-fired power plants with and without such advanced mitigation technologies. To our knowledge, this is the first Indian study dealing with LCA of Indian power plants with $\mathrm{SO}_{2}$ and $\mathrm{NO}_{x}$ mitigation technologies. A previous study (Agrawal et al. 2014) has focused on LCA of both coal and natural gas plants; however the impact of advanced mitigation technologies has not been discussed in that paper.

\subsection{Goals and scope}

The overarching objective of this paper is to perform environmental LCA of a typical Indian coal-fired power plant with and without $\mathrm{CO}_{2}, \mathrm{SO}_{2}$ and $\mathrm{NO}_{x}$ mitigation controls. Previous LCA studies used European/Chinese datasets for such analysis (Viebahn et al. 2014). The paper begins with development of normalization factors for India in various categories. The Eco-indicator 99 (EI99) methodology, which is a common methodology used across global studies uses European inventory data for 1999 , is used as the underlying methodology of this paper (Goedkoop and Spriensma 2000). However, we change the emissions and resource consumption datasets. This is warranted because the normalization factors in LCA largely depend on the relative emission levels and energy consumption. A large variation is observed between the inventories of India and other regions like Europe or China. For instance, the damage proportion of $\mathrm{CO}_{2}$ in the climate change category was $68.9 \%$ in the Indian scenario (Sharma et al. 2011), while it was $76 \%$ in the EI99 default scenario. Similar differences exist for other damage categories as well. Thus, we shall use Indian emissions and resource consumption data from 2008 to develop a new set of country-specific LCA normalization factors, which will be of use for future studies as well. Subsequently, emission inventory and coal consumption data for power plants with and without FGD, SCR and CCS technologies shall be developed using the Integrated Environmental Control Model (IECM) developed by the Carnegie Mellon University, USA, 1999. The two results shall be coupled to generate LCA results. This shall be done for a $500 \mathrm{MW}$ sub-critical and a $660 \mathrm{MW}$ super-critical plant.

It must be noted here that the power plant only is selected as the study definition area. That is, the boundary of the LCA study shall be the power plant only (and not preceding processes like coal mining, refining etc.). Also, for CCS, the transport and storage of $\mathrm{CO}_{2}$ shall not be taken into account. It is expected that the results generated in this paper will be extrapolated to a more extensive study which may include the preceding and consequent activities of the power plant.

\subsection{Impact of cultural theory on LCA}

Cultural theory has a significant impact on the LCA results. In the EI99 model, three versions of the damage model have been constructed. These are Egalitarian, Hierarchists and Individualists categories (Goedkoop and Spriensma 2000). These categories basically represent the perspective of the various types of people in a society. The type of perspective selected determines the normalization results and the weightage of different damage categories to the LCA. Table 1 includes some of the main differences between the three categories. The impact of cultural theory on the LCA of the plants has been discussed in detail in Sect. 4.

\subsection{Indian coal-fired power plants: the current scenario}

Coal has been the dominant fuel for electricity generation in India. The current installed capacity of coal-fired power plants is around $167 \mathrm{GW}$, which accounts for more than $60 \%$ of the total installed capacity (CEA 2015a, b). The larger availability and subsidized costing of coal in India plays a major role for the domination of coal based power in India. The increase in the pricing of power grade coal at lower calorific values is quite low. For example, the cost of coal increases from INR 620/t for the calorific value of $3100 \mathrm{kcal} / \mathrm{kg}$ coal to only INR $630 / \mathrm{t}$ for $4000 \mathrm{kcal} / \mathrm{kg}$ coal (Sen and Sarkar 2012). Recently, a large number of larger power plants have been coming up, including the ultramega power plants (UMPPs), which are super-critical power plants of around $4 \mathrm{GW}$. It is projected that between 2005 and 2030, the coal-fired power capacity will be added to the tune of $150 \mathrm{GW}$ (Nair et al. 2003). The older power plants in India are characterized by lower efficiency and higher emission and coal consumption rates (Kapila and Haszeldine 2009). Such plants may be refurbished or retrofitted with modern equipment to reduce the emissions 
Table 1 Objective comparison of the thinking characteristics of egalitarian, hierarchist and individualist perspectives (Thompson et al. 1990; Hofstetter 1998; Goedkoop and Spriensma 2000)

\begin{tabular}{llll}
\hline Prediction & Archetypes & & \\
\cline { 2 - 4 } & Egalitarian & Individualist & Hierarchist \\
\hline Criteria & Argument & Experience & Evidence \\
Management style & Preventive & Addaptive & Control \\
Distribution & Parity & Priority & Proportionality \\
Perception of time & Long term dominates short term & Short term dominates long term & Balanced distinction between short \\
& & & and long term \\
Intergeneration responsibility & Present $<$ future & Present $>$ future & Present = future \\
View of resources & Depleting & Abundance & Scarce \\
Perception of needs and & Can manage needs, but not & Can manage needs and & Can manage resources, but not \\
resources & resources & resources & needs \\
Energy future & Low growth (radical change now) & Business as usual & Middle of the road (technical fix) \\
Attitude to nature & Attentive & Laissez-faire & Regulatory \\
Attitude towards humans & Construct Egalitarian Society & Channel rather than change & Restrict behavior \\
Attitude towards resources & Need reducing strategy & Manage needs and resources & Increase resources \\
Perception (myth) of nature & Nature ephemeral & Nature benign & Nature perverse/tolerant \\
Perception of human nature & Born good, malleable & Self-seeking & Sinful \\
Attitude towards risk & Risk-aversive & Risk-seeking & Risk-accepting
\end{tabular}

and resource consumption levels. Also, for such plants a concrete renovation and modernization programme has been taken up to 2016-2017 (CEA 2009). Another recent feature is the setting up of super-critical units. Such units are being commissioned in the capacity of 660 and 800 MW (CEA 2013a, b). Commissioning of super critical plants has been put on more emphasis so as to improve the conversion efficiency and reduce the carbon footprint.

With the increasing trend of growth of coal-fuelled power stations, the fuel consumption and associated emissions are bound to see a substantial increase. As of 2013, the emission standards had limits only for particulate matter $\left(350 \mathrm{mg} / \mathrm{N} \mathrm{m}^{3}\right.$ for plants less than $210 \mathrm{MW}$ capacity and $150 \mathrm{mg} / \mathrm{Nm}^{3}$ for others), without any mandated standards for other pollutants, which were far higher than countries like Australia and the USA (Guttikunda et al. 2015). The Government has proposed new emission norms in April 2015, which are shown in Table 2 (MoEFCC 2015).

Water consumption has also been sought to be reduced in the new regulations. The new norms require power stations to install cooling towers and reduce water capacity to maximum $2.5-4 \mathrm{~m}^{3} / \mathrm{MW}$ h depending on the size of the plant (MoEFCC 2015). For coal consumption, the Indian regulations stipulate the maximum allowable unit heat rate and subsequently the coal consumption norms are defined for $85 \%$ capacity factor operation. For instance, for a subcritical plant of more than $250 \mathrm{MW}$, the maximum allowable heat rate is $2375 \mathrm{kcal} / \mathrm{kW}$ h and the consequent coal consumption allowed is $2899 \mathrm{t} / \mathrm{MW}$ annually for coal of $6100 \mathrm{kcal} / \mathrm{kg}$ heating value and $6316 \mathrm{t} / \mathrm{MW}$ annually for coal of $2800 \mathrm{kcal} / \mathrm{kg}$ heating value. The coal consumption rates allowed for super-critical plants for the aforementioned coals are $2746 \mathrm{t} / \mathrm{MW}$ and $5983 \mathrm{t} / \mathrm{MW}$ annually at a maximum allowable heat rate of $2250 \mathrm{kcal} / \mathrm{kW}$ h (CEA 2015a, b).

Land requirement of power plants also needs to be taken into account especially with regards to the challenge of land acquisition. Land requirement is specific on the basis of unit size and also the total number of units in the power plant. For instance, a $2 \times 500 \mathrm{MW}$ plant requires a total area of 1420 acres, out of which $31.6 \%$ is required for the power plant itself. Apart from that, area equal to $1 / 3 \mathrm{rd}$ of the plant is required to be given for the purposes of a green belt (CEA 2007).

\section{Methodology}

For this study, initially the normalization factors were developed using the Indian emissions and energy consumption data. These were coupled with the plant inventory consisting of the emissions and particulate emissions of a typical Indian coal-fired power plant. The analytical framework used to develop the final LCA is shown in Fig. 1, while the system life-cycle is depicted in Fig. 2. 
Table 2 Proposed new emission norms for Indian coal-fired power plants (MoEFCC 2015) (mg/N m³)

\begin{tabular}{llll}
\hline Emission type & Installation date & & After 2017 \\
\cline { 2 - 4 } & Before 2003 & 2003-2016 & 30 \\
\hline Particulate matter $(\mathrm{PM})$ & 100 & 50 & 100 \\
Sulphur dioxide $\left(\mathrm{SO}_{2}\right)$ & $600 ;$ for $<500 \mathrm{MW}$ & $200 ;$ for $>500 \mathrm{MW}$ & \\
& $200 ;$ for $>500 \mathrm{MW}$ & & 300 \\
Nitrogen oxides $\left(\mathrm{NO}_{x}\right)$ & 600 & 0.03 & 0.03 \\
Mercury $(\mathrm{Hg})$ & None; for $<500 \mathrm{MW}$ & & 100 \\
& $0.03 ;$ for $>500 \mathrm{MW}$ & & \\
\hline
\end{tabular}

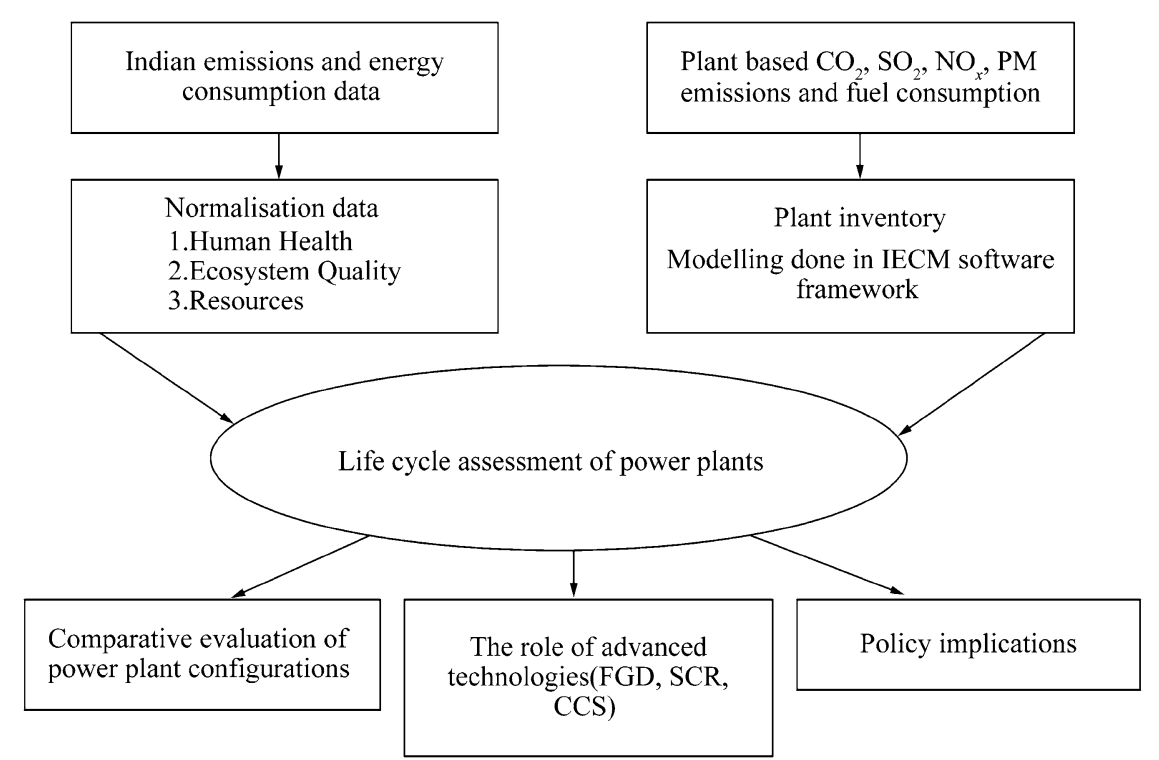

Fig. 1 Analytical framework for the study

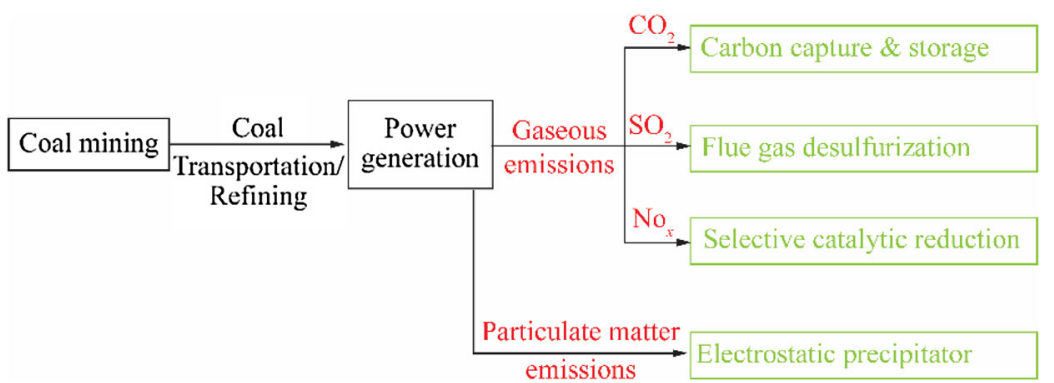

Fig. 2 System life cycle diagram for coal-fired power generation and emission mitigation. Notes The red text indicates the emitted substances and green text represents mitigation technologies

\subsection{Normalization}

In this study, the first step involved development of normalization factors for various categories of LCA. This includes human health, ecosystem quality and resources. The basic methodology of EI99 has been followed (Eco-
Indicator 2000). However, the normalization factors have been modified on the basis of Indian emissions and resource consumption data. This is with the understanding that the damage factors in the EI99 are constant for LCA across the world, however the normalized data varies. The data sources, along with the method of calculation for their 
use are presented in Table 3. We have used 2008 as the base year for calculation of the normalization factors. However, when data from 2008 is not available, the closest available data has been used, preferably not three years apart from 2008. It may be noted that the emissions in EI99 base case are for Europe in 1992 and we are using Indian data for 2008. The normalization factors are developed for three perspectives i.e. Egalitarians, Hierarchists and Individualists and for all the three damage categories. The exact calculations performed may be found in the Supplementary Information section.

Once the normalization factors for various damage categories have been computed, the respective damage factors are normalized according to them and then weighted using the default weighting factors of EI99. This is so because panel weighting is not within the scope of the present study. After normalization and weighting, we arrive at the final damage factors used to calculate the Environmental Impact of Electricity (EIE) for the substances of our interest. These are shown in Table 4.

\subsection{Plant inventory}

The plant inventory is made using the Integrated Environmental Control Model (IECM) developed by the Carnegie Mellon University, USA. This model is a multiparameter software platform which allows the user to configure a coal-fired power plant on the basis of base plant conditions, fuel type, auxiliary controls employed, etc. We have modeled a $500 \mathrm{MW}$ sub-critical unit and a $660 \mathrm{MW}$ super-critical unit. For modeling a typical Indian plant, we select Talcher coalfield, a sub-bituminous Gondwana coalfield as the coal linkage. The higher heating value (HHV) for this coal is $16,360 \mathrm{~kJ} / \mathrm{kg}$, carbon content is

Table 3 Data sources along with the method of calculation for various categories

\begin{tabular}{|c|c|c|c|c|c|}
\hline \multirow[t]{2}{*}{ Category } & \multirow[t]{2}{*}{ Data source } & \multirow[t]{2}{*}{ Method of calculation } & \multicolumn{3}{|c|}{ Normalization factor } \\
\hline & & & Egalitarian & Hierarchist & Individualist \\
\hline \multicolumn{3}{|l|}{ Human health } & $4.50 \times 10^{-3}$ & $4.45 \times 10^{-3}$ & $2.23 \times 10^{-3}$ \\
\hline $\begin{array}{l}\text { Respiratory } \\
\quad \text { (inorganic) }\end{array}$ & $\begin{array}{l}\text { Kurokawa et al. } \\
\text { (2013) }\end{array}$ & Direct Emissions have been provided & $4.15 \times 10^{-3}$ & $4.11 \times 10^{-3}$ & $1.90 \times 10^{-3}$ \\
\hline $\begin{array}{r}\text { Respiratory } \\
\text { (organic) }\end{array}$ & $\begin{array}{l}\text { Kurokawa et al. } \\
\text { (2013) }\end{array}$ & Direct Emissions have been provided & $1.76 \times 10^{-5}$ & $1.76 \times 10^{-5}$ & $1.64 \times 10^{-5}$ \\
\hline $\begin{array}{l}\text { Climate } \\
\text { change }\end{array}$ & $\begin{array}{l}\text { Sharma et al. } \\
\text { (2011) }\end{array}$ & $\begin{array}{l}\text { Calculation based on total Global Warming Potential } \\
\text { (GWP) of Greenhouse Gases (GHGs). The total GHG } \\
\text { emissions of India have been compared with EI99 case } \\
\text { to arrive at the value }\end{array}$ & $3.27 \times 10^{-4}$ & $3.27 \times 10^{-4}$ & $3.14 \times 10^{-4}$ \\
\hline Radiation & $\begin{array}{l}\text { Multiple sources; } \\
\text { see } \\
\text { supplementary } \\
\text { materials }\end{array}$ & $\begin{array}{l}\text { Total nuclear electricity generation has been compared for } \\
\text { India and France. Subsequently, the final value has been } \\
\text { calculated }\end{array}$ & $2.31 \times 10^{-7}$ & $2.31 \times 10^{-7}$ & $2.26 \times 10^{-8}$ \\
\hline \multicolumn{3}{|c|}{ Ecosystem quality } & $4.50 \times 10^{3}$ & $4.50 \times 10^{3}$ & $2.84 \times 10^{3}$ \\
\hline Ecotoxicity & $\begin{array}{l}\text { Multiple sources; } \\
\text { see } \\
\text { supplementary } \\
\text { materials }\end{array}$ & $\begin{array}{l}\text { Comparison of Biochemical Oxygen Demand (BOD) and } \\
\text { water area of Europe and India }\end{array}$ & $2.15 \times 10^{3}$ & $2.15 \times 10^{3}$ & $4.83 \times 10^{2}$ \\
\hline $\begin{array}{l}\text { Acidification/ } \\
\text { nutrification }\end{array}$ & $\begin{array}{l}\text { Kurokawa et al. } \\
\text { (2013) }\end{array}$ & Direct Emissions have been provided & $1.87 \times 10^{2}$ & $1.87 \times 10^{2}$ & $1.87 \times 10^{2}$ \\
\hline Land use & $\begin{array}{l}\text { Multiple sources; } \\
\text { see } \\
\text { supplementary } \\
\text { materials }\end{array}$ & Categorized land use data is available on GoI databases & $2.17 \times 10^{3}$ & $2.17 \times 10^{3}$ & $2.17 \times 10^{3}$ \\
\hline Resources & & & $1.03 \times 10^{3}$ & $8.21 \times 10^{2}$ & $8.22 \times 10^{1}$ \\
\hline Minerals & $\begin{array}{l}\text { Multiple sources; } \\
\text { see } \\
\text { supplementary } \\
\text { materials }\end{array}$ & & $8.22 \times 10^{1}$ & $8.22 \times 10^{1}$ & $8.22 \times 10^{1}$ \\
\hline Fossil & $\begin{array}{l}\text { Garg and Shukla } \\
\text { (2009) }\end{array}$ & & $9.43 \times 10^{2}$ & $7.39 \times 10^{2}$ & 0 \\
\hline
\end{tabular}

The last column shows the normalization factor developed for India on a per-inhabitant basis 
Table 4 Final damage factors (normalized and weighted), hereafter referred to as $b$

\begin{tabular}{llll}
\hline Element & Egalitarian & Hierarchist & Individualist \\
\hline $\mathrm{CO}_{2}$ & $1.4 \times 10^{-2}$ & $1.89 \times 10^{-2}$ & $4.93 \times 10^{-2}$ \\
$\mathrm{SO}_{2}{ }^{*}$ & $3.65\left(3.64+1.16 \times 10^{-2}\right)$ & $5.00\left(4.91+9.25 \times 10^{-2}\right)$ & $9.71\left(9.62+9.16 \times 10^{-2}\right)$ \\
$\mathrm{NO}_{x}{ }^{*}$ & $6.58\left(5.94+6.35 \times 10^{-1}\right)$ & $8.48(7.97+0.51)$ & $0.79\left(2.93 \times 10^{-1}+0.50\right)$ \\
$\mathrm{Coal}$ & $3.96 \times 10^{-1}$ & $6.13 \times 10^{-2}$ & 0.00 \\
$\mathrm{PM}$ & 25 & 33.71 & 67.57
\end{tabular}

* $\mathrm{SO}_{2}$ and $\mathrm{NO}_{x}$ cause damage in two categories, viz respiratory (Inorganic) and acidification. The first term in the parentheses indicated the damage factor for respiratory (Inorganic), while the second is that for acidification

$40.56 \%$, sulphur content is $0.38 \%$ and ash percentage is $40 \%$ (Chandra and Chandra 2004). The boiler efficiency for a sub-critical plant is assumed to be $82 \%$ and that for a super-critical plant is assumed to be $86 \%$ (Singh and Rao 2014a). Four configurations of the plant are modeled:

(1) Base plant-only with particulate matter control.

(2) With $\mathrm{CO}_{2}$ capture-This configuration encompasses within it $\mathrm{SO}_{2}, \mathrm{NO}_{x}$ and additional $\mathrm{PM}$ controls, without which the performance of the $\mathrm{CO}_{2}$ capture unit may reduce in due course of time (Rao and Rubin 2006). We consider monoethanol amine (MEA) based capture for modeling this configuration.

(3) With FGD for $\mathrm{SO}_{2}$ controls.

(4) With FGD for $\mathrm{SO}_{2}$ controls and SCR for $\mathrm{NO}_{x}$ controls.

The plant inventory data for the modeled plants is shown in Tables 5 and 6.

Subsequently, the following equation is applied to obtain the environmental impact of electricity (EIE) in case of various plant configurations (Petrakopoulou and Tsatsaronis 2014):

$E I E=b_{f} m_{f}+\sum b_{e} m_{e}$

where $b_{f}$ represents the normalized factor for coal, $b_{e}$ stands for the normalized factor for each pollutant (both from Table 4) while $m_{f}$ denotes the coal consumption of the plant and $m_{e}$ stands for emission of a particular pollutant in the plant inventory (both from Tables 5 and 6).

\section{Result and discussion}

The EIE has been calculated for various configurations of plants and for different perspectives. The results for the sub-critical plant are shown in Table 7, while those for super-critical plant are shown in Table 8.

It may be noted that the scores obtained in Tables 7 and 8 are different from the ones calculated in Petrakopoulou and Tsatsaronis (2014) due to different weighting procedures. As expected, the environmental impact of the supercritical plant is substantially less than that of the sub-critical plant due to lower emissions and fuel consumption. The relative environmental impacts of the various configurations depend largely on the perspective used.

In the egalitarian perspective, it is found that the mitigation technologies do not show a very positive impact on the environmental impact. For example, the use of CCS increases the EIE over the base plant by $35 \%$ for the subcritical plant and $25 \%$ for the super-critical plant (Fig. 3). This is so because the damage prevented by reduction in $\mathrm{CO}_{2}$ and $\mathrm{SO}_{2}$ emissions is considerably less than the damage incurred due to the increase in fossil fuel resource requirement. Thus, under the egalitarian perspective, the use of CCS may be discouraged. The use of FGD alone

Table 5 Plant inventory for $500 \mathrm{MW}_{\text {net }}$ plant with and without emission controls

\begin{tabular}{lllll}
\hline Parameter & Base plant & CCS & FGD & FGD + SCR \\
\hline Gross size (MW) & 529.9 & 611.2 & 540.1 & 543.8 \\
Net size $(\mathrm{MW})$ & 500.0 & 500.0 & 500.0 & 500.0 \\
Coal input $(\mathrm{kg} / \mathrm{kW} \mathrm{h)}$ & 0.6499 & 0.9691 & 0.6624 & 0.6670 \\
$\mathrm{CO}_{2}$ emissions $(\mathrm{kg} / \mathrm{kW} \mathrm{h)}$ & 0.9647 & 0.1438 & 0.9856 & 0.9923 \\
$\mathrm{SO}_{2}$ emissions $(\mathrm{kg} / \mathrm{kW} \mathrm{h)}$ & $4.774 \times 10^{-3}$ & 0 & $1.505 \times 10^{-3}$ & $1.504 \times 10^{-3}$ \\
$\mathrm{NO}_{x}$ emissions $(\mathrm{kg} / \mathrm{kW} \mathrm{h)}$ & $3.26 \times 10^{-3}$ & $4.78 \times 10^{-3}$ & $3.33 \times 10^{-3}$ & $4.71 \times 10^{-4}$ \\
$\mathrm{PM}_{0}$ emissions $(\mathrm{kg} / \mathrm{kW} \mathrm{h)}$ & $9.2 \times 10^{-5}$ & $6.89 \times 10^{-5}$ & $9.4 \times 10^{-5}$ & $9.48 \times 10^{-5}$ \\
\hline
\end{tabular}


Table 6 Plant inventory for $660 \mathrm{MW}_{\text {net }}$ plant with and without emission controls

\begin{tabular}{lllll}
\hline Parameter & Base plant & CCS & FGD & FGD + SCR \\
\hline Gross size (MW) & 696.5 & 785.3 & 708.6 & 712.9 \\
Net size $(\mathrm{MW})$ & 660.0 & 660.0 & 660.0 & 660.0 \\
Coal input $(\mathrm{kg} / \mathrm{kW} \mathrm{h)}$ & 0.5829 & 0.8151 & 0.5931 & 0.5967 \\
$\mathrm{CO}_{2}$ Emissions $(\mathrm{kg} / \mathrm{kW} \mathrm{h)}$ & 0.8653 & 0.1210 & 0.8823 & 0.8877 \\
$\mathrm{SO}_{2}$ emissions $(\mathrm{kg} / \mathrm{kW} \mathrm{h)}$ & $4.282 \times 10^{-3}$ & 0 & $1.347 \times 10^{-3}$ & $1.346 \times 10^{-3}$ \\
$\mathrm{NO}_{x}$ emissions $(\mathrm{kg} / \mathrm{kW} \mathrm{h)}$ & $2.93 \times 10^{-3}$ & $4.02 \times 10^{-3}$ & $2.98 \times 10^{-3}$ & $4.21 \mathrm{E} \times 10^{-4}$ \\
$\mathrm{PM}_{10}$ emissions $(\mathrm{kg} / \mathrm{kW} \mathrm{h)}$ & $8.28 \times 10^{-5}$ & $5.79 \times 10^{-5}$ & $8.42 \times 10^{-5}$ & $8.48 \times 10^{-5}$ \\
\hline
\end{tabular}

Table 7 EIE score for various configurations and perspectives of the 500 MW sub-critical plant

\begin{tabular}{llll}
\hline Item & Egalitarian & Hierarchist & Individualist \\
\hline Base plant & 0.31 & 0.11 & 0.10 \\
$w(\mathrm{CCS})$ & 0.42 & 0.10 & 0.02 \\
$w(\mathrm{FGD})$ & 0.31 & 0.09 & 0.07 \\
$w(\mathrm{FGD}+\mathrm{SCR})$ & 0.29 & 0.07 & 0.07 \\
\hline
\end{tabular}

Table 8 EIE score for various configurations and perspectives of the $660 \mathrm{MW}$ super-critical plant

\begin{tabular}{llll}
\hline Item & Egalitarian & Hierarchist & Individualist \\
\hline Base plant & 0.28 & 0.101134 & 0.092147 \\
$w(\mathrm{CCS})$ & 0.35 & 0.088294 & 0.013053 \\
$w(\mathrm{FGD})$ & 0.27 & 0.087876 & 0.06462 \\
$w($ FGD + SCR $)$ & 0.26 & 0.066514 & 0.062896 \\
\hline
\end{tabular}

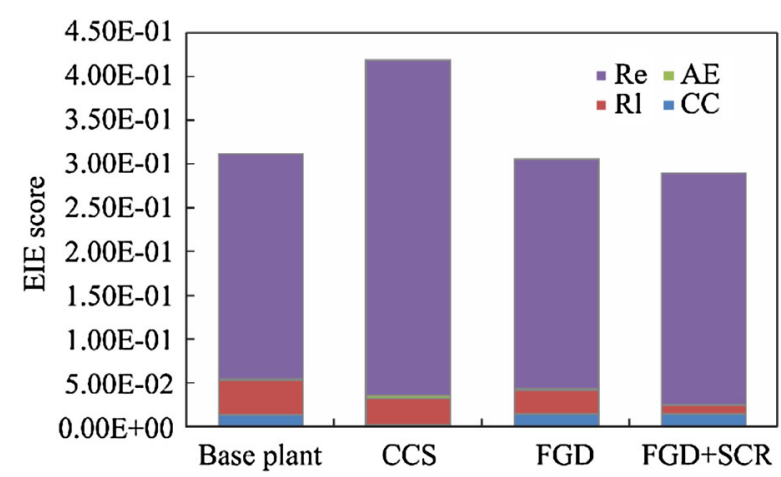

Fig. 3 EIE for four plant configurations, presented sectorally for different damage categories in the egalitarian perspective

also is not very beneficial in this perspective because the environmental benefits are very small. However, when FGD is used in conjunction with SCR technology to cause both $\mathrm{SO}_{2}$ and $\mathrm{NO}_{x}$ control, the environmental benefits are more amplified.
It can be seen that the most dominating damage category is the resource category followed by the respiratory (inorganic) category. The damage in the acidification and eutrophication category is negligible (less than $1 \%$ across different plant configurations). Moreover, the impact in the climate change category is also low due to which the effect of CCS is not so profound.

In the hierarchist perspective, the use of CCS, FGD and FGD + SCR configurations is more preferred. However, the difference in EIE is low as shown in Fig. 4. Thus, the use of CCS may not be justified in spite of the environmental benefits if the cost of $\mathrm{CO}_{2}$ capture remains at the current levels. However, the use of FGD and SCR may prove to be advantageous due to the not-so-high costs. Thus, we echo the findings of Singh and Rao (2015) in favor of the use of FGD and SCR technologies in Indian coal-fired power plants.

In the hierarchist perspective, resources and the respiratory (inorganic) category are the two most important damage categories, occupying between $74 \%$ and $95 \%$ of the total damage for various configurations. The total proportion of damage in the acidification category is more than that in the egalitarian perspective but still the lowest. Climate change also becomes a more important damage category accounting for more than $16 \%$ damage in the

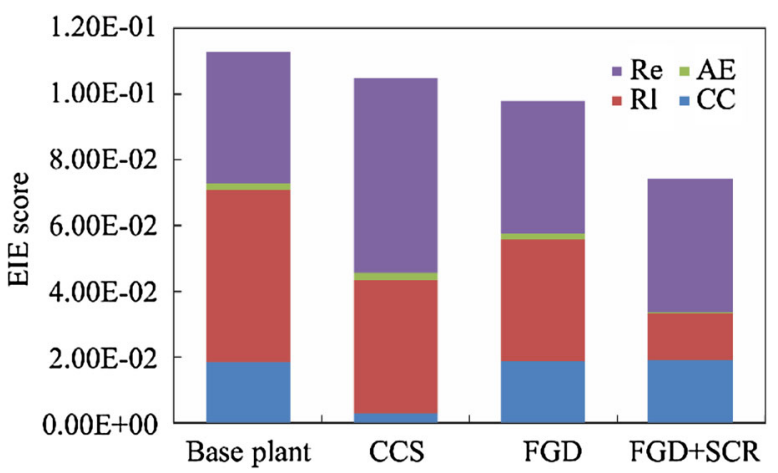

Fig. 4 EIE for four plant configurations, presented sectorally for different damage categories in the hierarchist perspective 
base plant case and $25 \%$ damage in the FGD + SCR configuration.

The real thrust for CCS technology is seen in the individualist perspective. This is so because in this perspective, there is no consideration of depletion of fossil fuel reserves. As a result, the reduction in gaseous emissions shows a favorable scenario for the use of this technology. In this perspective, for the base plant, climate change is responsible for close to $43 \%$ of the total damage (Fig. 5). With the usage of CCS, the share of damage due to climate change drops to around $25 \%$. Also, the total environmental damage drops by approximately $75 \%$, which is an indicator of the enormous benefits of the CCS technology. The EIE due to usage of electricity drops by $27 \%$ in the FGD only configuration and $36 \%$ for the FGD + SCR configuration.

It is also prudent to analyze the contribution of individual units to the overall EIE. We have restricted our analysis to the electricity generating unit itself. We find that in the CCS configuration, the $\mathrm{CO}_{2}$ capture unit contributes to $9.06 \%$ of the EIE in the egalitarian perspective and $5.60 \%$ of the EIE in the hierarchist perspective. Also, for the FGD + SCR configuration, the EIE associated with the FGD and SCR units is $0.40 \%$ and $0.12 \%$ in the egalitarian perspective. However, the combined effect of the two units put together is less than $0.10 \%$ of the total EIE in the hierarchist perspective. This shows why the futuristic plant technologies should be used, as they have minimal impact to the environment, even taking into account the energy penalty. In other words, the contribution analysis shows that these technologies will do much more "good-than-harm" if brought down to suitably low cost levels.

It is prudent to analyze the impact of sensitivity of the plant parameters to the final EIE score of the plants. This includes the variabilities and uncertainties in the various parameters within the base plant and the futuristic plant configurations.

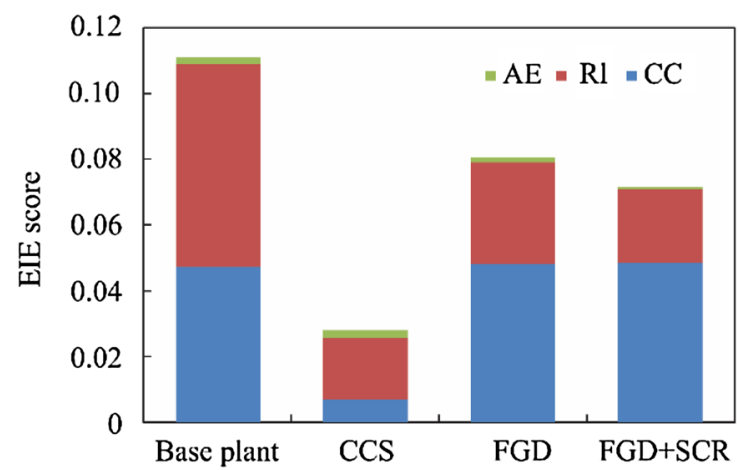

Fig. 5 EIE for four plant configurations, presented sectorally for different damage categories in the individualist perspective
The impacts of sensitivity on the value of $b_{\mathrm{CO}_{2}}$ and $b_{f}$ on the EIE score of the plants have been analyzed in Figs. 6, 7 and 8 . We shall try to investigate the effect of sensitivity in effect of $\mathrm{CO}_{2}$ and coal usage to the overall impact on EIE. As with the case in Petrakopoulou and Tsatsaronis (2014), the value of $b$ has been varied from zero to approximately five times the default values calculated in Table 4. Further, the impact of plant efficiency on the EIE has also been studied. The baseline efficiency of the reference plant (in the sub-critical) case is found to be $33.89 \%$. This is varied from $33 \%$ to $34.5 \%$ to see the amount of difference caused to the EIE. As expected, the slope of increase of the EIE is less for the CCS case for significantly lower $\mathrm{CO}_{2}$ emissions. For the egalitarian perspective, even at the highest value of $b_{\mathrm{CO}_{2}}$, CCS does not become an environmentally feasible option. However, at higher values of $b_{\mathrm{CO}_{2}}$, the difference between the EIEs of the CCS configuration and other configurations reduce considerably below the base case. Of course, with increase in $b_{f}$, the EIE score for CCS increases much above the EIE for other configurations, owing to the significantly large energy penalty. In the hierarchist perspective, a higher $b_{\mathrm{CO}_{2}}$ leads to a more favorable scenario for CCS.

An important factor that affects the overall EIE of the plant is the net plant efficiency. The effect of plant
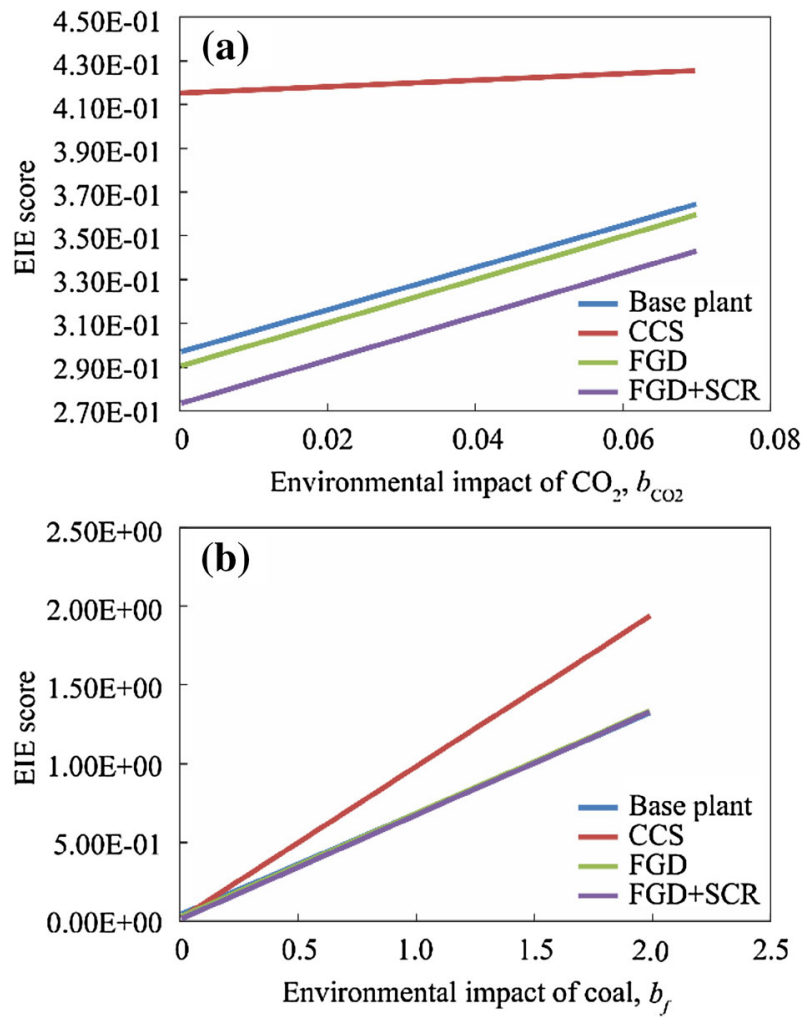

Fig. 6 Effect of sensitivity of impact of $\mathbf{a} \mathrm{CO}_{2}$, b coal on EIE for different plant configurations for egalitarian perspective 

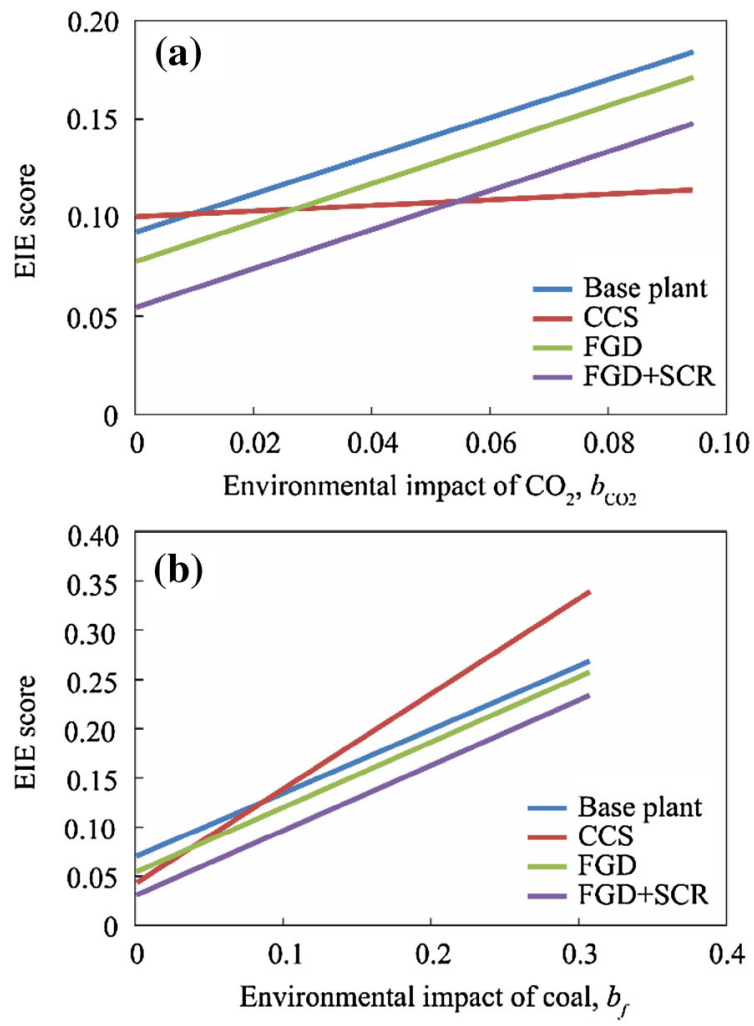

Fig. 7 Effect of sensitivity of impact of $\mathbf{a ~} \mathrm{CO}_{2}$, b coal on EIE for different plant configurations for hierarchist perspective

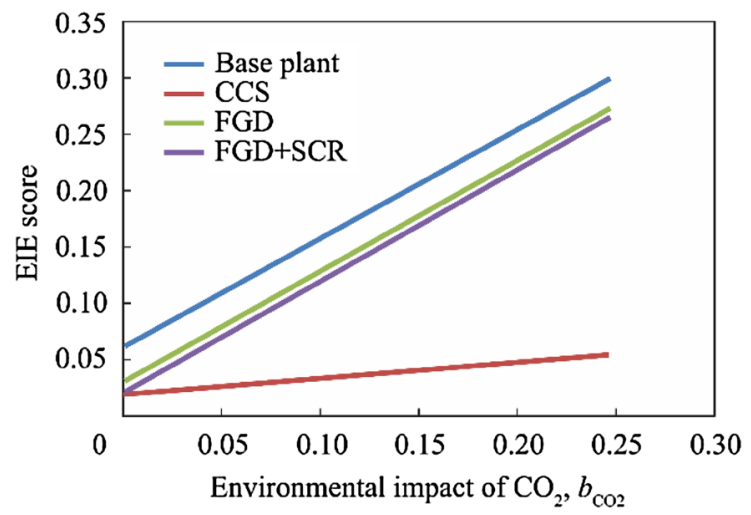

Fig. 8 Effect of sensitivity of impact of $\mathbf{a} \mathrm{CO}_{2}$, $\mathbf{b}$ coal on EIE for different plant configurations for individualist perspective

efficiency on EIE is illustrated in Fig. 9. It is found that in the non-CCS plant configurations, for an increase in the plant efficiency by 0.5 percentage points, the EIE reduces by $1.5 \%$. For the CCS case, this increases to more than $2 \%$. Thus, there is a considerable improvement in air quality if the plants of that area improve the plant efficiency. This is so because with improvements in efficiency, the amount of coal combusted for each MW power reduces, thereby also reducing the corresponding gaseous and particulate emissions.

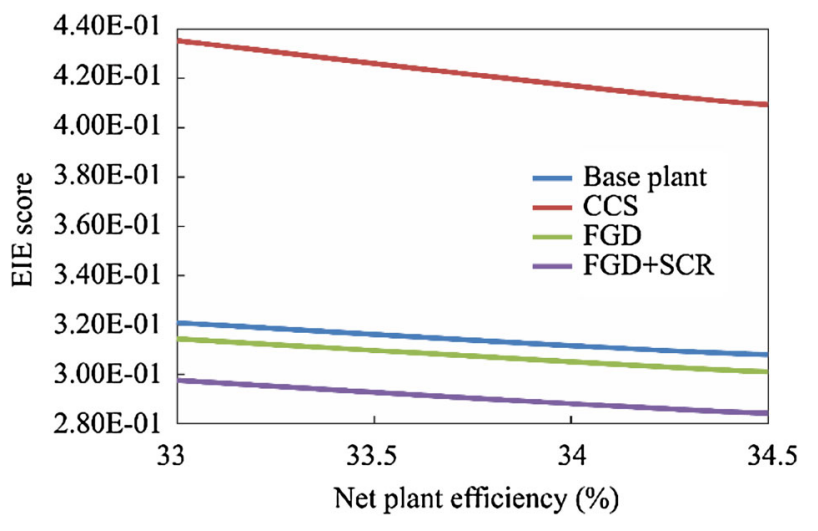

Fig. 9 Effect of plant efficiency on the EIE in egalitarian perspective

We have also tried to perform sensitivity analysis on individual technology parameters. We have studied the effect of variation in the $\mathrm{CO}_{2}$ capture parameters as suggested previously in the literature (Abu-Zahra et al. 2007; Singh and Rao 2014a, b). For CCS, we have analysed five parameters and their effect of variation for the three perspectives as illustrated in Fig. 10. The parameters related to $\mathrm{CO}_{2}$ capture have a significant impact on the EIE. For example, if the capture rate is reduced to $70 \%$ (from the default $90 \%$ ), the EIE in egalitarian perspective decreases by $\sim 7 \%$, while the increase in the hierarchist perspective is close to $5 \%$. In the individualist perspective, the EIE increases by almost $75 \%$ as coal consumption (which decreases with decrease in capture rate), is not a consideration in this perspective. The effect of all other parameters studied is almost similar for all the other perspectives, as can be seen by comparing Fig. 10(a), (b) and (c). It has been found out the parameters related to $\mathrm{SO}_{2}$ and $\mathrm{NO}_{x}$ controls do not lead to any significant deviation in the EIE. For all the parameters studied, the deviation is less than $1 \%$.

\section{Conclusions}

In this paper a comparative environmental LCA of a typical Indian coal-fired power plant with and without advanced mitigation control strategies has been carried out. In this process, new normalization factors for life cycle assessment in India have also been developed.

Using the new normalization factors developed in this study, a more accurate assessment of the environmental benefits of $\mathrm{CO}_{2}, \mathrm{NO}_{x}$ and $\mathrm{SO}_{2}$ mitigation technologies has been made. For $\mathrm{SO}_{2}$ and $\mathrm{NO}_{x}$ control strategies pertaining to coal-fired power plants, this happens to be the first Indian study, to the best of our knowledge. Also, for CCS, Indian datasets have been used, as compared to the previous study by Viebahn et al. (2014), who used European and 

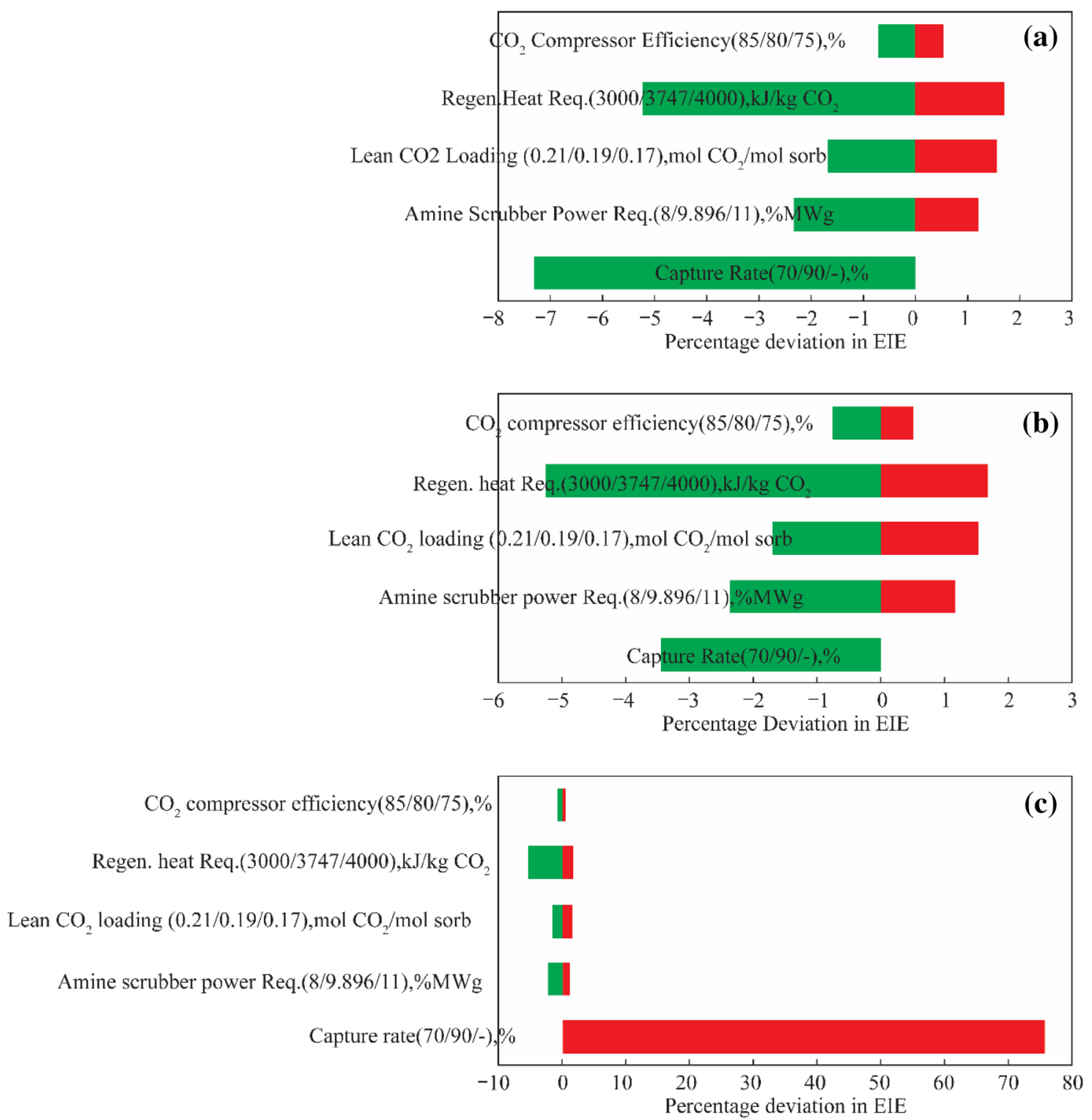

Fig. 10 Percentage deviation in EIE due to change in parameters of the $\mathrm{CO}_{2}$ capture unit. a Egalitarian, b Hierarchist and c Individualist perspectives. The left value in the parenthesis indicates the value of the parameter, leading to lowest EIE, the middle value indicates the nominal or default value and the right value indicates the value leading to maximum EIE

Chinese datasets. The previous study used different categories to evaluate the overall LCA of the power plants. But, in this paper, a final EIE or environmental impact of electricity score has been calculated to give our assessment about the damage to the environment.

The results show that in all the perspectives, it is imperative to use $\mathrm{SO}_{2}$ and $\mathrm{NO}_{x}$ mitigation technologies in our coal-fired power plants as there is a substantive decrease in the EIE in all the three perspectives. The usage of CCS largely depends on the perspective. The scenario is unfavorable towards CCS in the egalitarian perspective, almost neutral in the hierarchist perspective and quite favorable in the individualist perspective. This is coherent with the real situation of CCS as its implementation is largely driven by the attitude of the stakeholders in government, industry and academia. Currently, the stance of the Government of India is not so favorable towards CCS owing to the very high costs and large energy penalty (Kapila and Haszeldine 2009). Therefore, if in the future, the energy penalty and costs for implementing CCS in Indian power plants come down, it will lead to a compounded decrease in EIE for CCS, i.e. change due to the engineering and physical conditions of the plant and also the changed attitude of the government, which may consider the technology more favorably.

The costs as well as the energy penalty for implementation of FGD and SCR in Indian power plants are quite low, i.e. the increase in cost of electricity is less than $15 \%$ 
of the current electricity costs (Singh and Rao 2015). Also, as seen in this paper, there is a consistent environmental benefit attached with these technologies. Therefore, it is suggested that both these technologies may be made a mandatory requirement for all the future power plants beyond a certain capacity and also the larger plants currently under operation may be retrofitted with such systems. Of course, more India-centric research may be carried out in the technical domains of these technologies to make the correct decisions with regard to the chemical reagents, $\mathrm{SO}_{2} / \mathrm{NO}_{x}$ removal efficiency and so on. The usage of FGD and SCR is likely to enhance overall environmental quality of the areas adjoining the power plants.

However, despite the useful results developed in this study, it would be useful to couple the life cycle balance of the adjoining areas, such as coal mines, coal transport and $\mathrm{CO}_{2}$ storage alongwith this study, to give a more enhanced view of the environmental impacts of Indian coal-fired power plants.

Open Access This article is distributed under the terms of the Creative Commons Attribution 4.0 International License (http://creative commons.org/licenses/by/4.0/), which permits unrestricted use, distribution, and reproduction in any medium, provided you give appropriate credit to the original author(s) and the source, provide a link to the Creative Commons license, and indicate if changes were made.

\section{References}

Abu-Zahra MR, Niederer JP, Feron PH, Versteeg GF (2007) $\mathrm{CO}_{2}$ capture from power plants: part II. A parametric study of the economical performance based on mono-ethanolamine. Int $\mathrm{J}$ Greenhouse Gas Control 1:135-142

Agrawal KK, Jain S, Jain AK, Dahiya S (2014) Assessment of greenhouse gas emissions from coal and natural gas thermal power plants using life cycle approach. Int J Environ Sci Technol 11:1157-1164

CEA (2007) Report on the land requirement of thermal power plants. Central Electricity Authority, New Delhi

CEA (2009) National perspective plan for renovation, modernisation and life extension of thermal power plants. Central Electricity Authority, New Delhi

CEA (2013) Growth of Electricity Sector in India from 1947-2013. Central Electricity Authority. www.cea.nic.in/reports/planning/ dmlf/growth.pdf. Accessed 2 October 2015

CEA (2013b) Standard technical features of BTG system for supercritical 660/800 MW thermal units. Central Electricity Authority, New Delhi

CEA (2015) All-India installed capacity (in MW) of power stations as on 31.07.2015. Central Electricity Authority. http://www.cea.nic. in/reports/monthly/inst_capacity/jul15.pdf. Accessed on 02.10 .2015

CEA (2015) Norms for coal consumption in TPPs issued on 15.01.2015. Central Electricity Authority. www.cea.nic.in/ reports/articles/thermal/coal_cons_norms.pdf.

Accessed 02.10 .2015

Chandra A, Chandra H (2004) Impact of Indian and imported coal on Indian thermal power plants. J Sci Ind Res 63:156-162
Chikkatur AP, Sagar AD, Sankar TL (2009) Sustainable development of the Indian coal sector. Energy 34:942-953

Garg A, Shukla PR (2009) Coal and energy security for India: role of carbon dioxide $\left(\mathrm{CO}_{2}\right)$ capture and storage (CCS). Energy 34:1032-1041

Garg A, Shukla PR, Kapshe M (2006) The sectoral trends of multigas emissions inventory of India. Atmos Environ 40:4608-4620

Goedkoop M, Spriensma R (2000) The eco-indicator 99-a damage oriented method for Life Cycle Impact Assessment, PRé Consultants B.V

Guttikunda SK, Jawahar P (2014) Atmospheric emissions and pollution from the coal-fired thermal power plants in India. Atmos Environ 92:449-460

Guttikunda S, Jawahar P, Goenka D (2015) Regulating air pollution from coal-fired power plants in India. Econ Polit Wkly 50:62-67

Hofstetter P (1998) Perspectives in life cycle impact assessment: a structured approach to combine models of the technosphere, ecosphere and valuesphere. Kluwer Academic Publishers, Norwell

IPCC (2005) Special report on $\mathrm{CO}_{2}$ capture and storage. Cambridge University Press, UK

Kapila RV, Haszeldine RS (2009) Opportunities in India for carbon capture and storage as a form of climate change mitigation. Energy Procedia 1:4527-4534

Karmakar S, Kolar AK (2013) Thermodynamic analysis of high-ash coal-fired power plant with carbon dioxide capture. Int J Energy Res 37:522-534

Kurokawa J, Ohara T, Morikawa T, Hanayama S, Janssens-Maenhout G, Fukui T,... Akimoto H (2013) Emissions of air pollutants and greenhouse gases over Asian regions during 2000-2008: Regional Emission inventory in ASia (REAS) version 2. Atmospheric Chemistry and Physics 13:11019-11058

MoEFCC (2015) Draft Notification for inviting the Public comments for Coal based Thermal Power Plants. Ministry of Environment, Forests and Climate Change, Government of India. http://envfor. nic.in/content/draft-notification-inviting-public-comments-coalbased-thermal-power-plant. Accessed 02.10.2015

Petrakopoulou F, Tsatsaronis G (2014) Can carbon dioxide capture and storage from power plants reduce the environmental impact of electricity generation? Energy Fuels 28:5327-5338

Rao AB, Rubin ES (2006) Identifying cost-effective $\mathrm{CO}_{2}$ control levels for amine-based $\mathrm{CO}_{2}$ capture systems. Ind Eng Chem Res 45:2421-2429

Rubin ES, Taylor MR, Yeh S, Hounshell DA (2004) Learning curves for environmental technology and their importance for climate policy analysis. Energy 29:1551-1559

Sen K, Sarkar A (2012) Grading and pricing of power coals-some suggestions. In: Coal as dominant fuel for power plants: issues \& challenges, STEAG Energy Services (India), New Delhi

Sharma SK, Choudhury A, Sarkar P, Biswas S, Singh A, Dadhich PK, ...Chauhan R (2011) Greenhouse gas inventory estimates for India. Current Science 101:405-415

Singh U, Rao AB (2014a). Prospects of carbon capture and storage (CCS) for new Coal Power Plants in India. In: 1st National Conference on Advances in Thermal Engineering, Indian School of Mines Dhanbad, pp 165-174

Singh U, Rao AB (2014b). Estimating the environmental implications of implementing carbon capture and storage in Indian coal power plants. In: 2014 International Conference on Advances in Green Energy, IEEE, pp 226-232

Singh $\mathrm{U}$, Rao $\mathrm{AB}$ (2015) Integrating $\mathrm{SO}_{2}$ and $\mathrm{NO}_{x}$ control systems in Indian coal-fired power plants. Decision 42:191-209

Thompson M, Ellis R, Wildavsky A (1990) Cultural theory. Westview Print, Boulder

Viebahn P, Vallentin D, Höller S (2014) Prospects of carbon capture and storage (CCS) in India's power sector-An integrated assessment. Appl Energy 117:62-75 